CDD: 370.78

\title{
VALORIZANDO A LEITURA EPISTEMOLÓGICA NA PESQUISA EM EDUCAÇÃo
}

\author{
Susy Cristina Rodrigues
}

\begin{abstract}
RESUMO: Demonstramos neste trabalho a importância dos estudos sobre a epistemologia para problematização, desconstrução de preconceitos e contribuição na elaboração qualificada na produção de conhecimento científico. É apresentada a leitura epistemológica de uma pesquisa concluída com o título: "A adolescência inventada e os sujeitos que se inventam na participação social: capturas e rupturas" (CAMPOS, 2008), com base teórica em Sánchez Gamboa (2012, 2013). Ao final desta leitura, após identificar a matriz paradigmática entre a construção da pergunta e da resposta na referida pesquisa, propõe-se o pensamento sobre os limites, erros, acertos e escolhas na pesquisa, a partir do valor da epistemologia.
\end{abstract}

PALAVRAS-ChAVE: Epistemologia. Pesquisa. Educação.

\section{VALUING THE EPISTEMOLOGICAL READING IN EDUCATIONAL RESEARCH}

\begin{abstract}
We have shown here the importance of studies of epistemology for questioning, deconstructing prejudices and contribution to the qualified elaboration in the production of scientific knowledge. The epistemological reading of a survey completed with the title appears: "The invented adolescence and the subjects who invent themselves in the social participation: captures and ruptures" (CAMPOS, 2008), with theoretical basis of Sánchez Gamboa $(2012,2013)$. At the end of this reading, after identifying the paradigmatic matrix between the construction of question and answer in this research, we propose thinking about the limits, mistakes, successes and choices in the research, based on the value of epistemology.
\end{abstract}

Keywords: Epistemology. Research. Education.

\section{VALORANDO LA LECTURA EPISTEMOLÓGICA EN LA INVESTIGACIÓN EDUCATIVA}

RESUMEN: Hemos demostrado aquí la importancia de los estudios de la epistemología para ser interrogado, la deconstrucción de prejuicios y la contribución a la elaboración cualificad en la producción de conocimiento científico. La lectura epistemológica de una encuesta realizada con el título aparece: "La adolescencia inventó y asignaturas que se inventaron en la participación social: capturas y rupturas" (CAMPOS, 2008), con base teórica de Sánchez Gamboa (2012, 2013). Al final de esta lectura, después de identificar la matriz paradigmática entre la construcción de la pregunta y la respuesta en esta investigación, se propone pensar en los límites, los errores, los éxitos y las opciones en la investigación, a partir del valor de la epistemología.

PALABRAS-CLAVE: Epistemología. Investigación. Educación.

\footnotetext{
${ }^{1}$ Bacharel em Serviço Social pela Pontifícia Universidade Católica de Campinas (PUC-Campinas). Mestranda em Educação pela UNICAMP. Bolsista CAPES. Pesquisadora do VIOLAR - Laboratório de Estudos sobre Violência, Imaginário e Juventude/Fac. Educação/UNICAMP. E-mail: susy_crs@yahoo.com.br
}

Recebido em: 24/01/2014 - Aceito em: 24/04/2014.

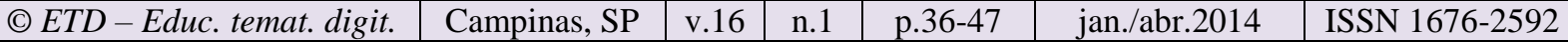




\section{POR QUe precisamos VAlorizar mais a ePIStemologia nas PESQUISAS?}

A escrita deste artigo partiu da iniciativa de entender a importância da epistemologia na pesquisa em educação para problematização, desconstrução de preconceitos, reflexão e contribuição na produção de conhecimento com qualidade.

Com o suporte dos principais teóricos elencados: Sánchez (2013), Cortella (2001), Alves-Mazzotti e Gewandsznajder (2001), Romano (1998) e Granger (1994), propõe-se pensar acerca dos limites, erros e acertos nas pesquisas envolvendo os aspectos técnicos, teóricos, metodológicos, epistemológicos, gnosiológicos e ontológicos, suscitando a ampliação dos horizontes sobre os pontos de vista da epistemologia.

Segundo Sánchez Gamboa (2013, p. 43-44), na Grécia antiga existiam formas de conhecimento predominantes, conhecidos como racionalidade mítica (mythos) e senso comum (doxa), com fins de responder as múltiplas indagações existentes na sociedade. Surgiram filósofos que orientaram essas respostas baseadas em um conhecimento lógico, mais confiável e verificável. A busca por respostas disciplinadas com princípios lógicos e com algumas regras básicas denominaram o conhecimento de sofia (filosofia) e de episteme (conhecimento científico). Assim, a produção do conhecimento científico se expressa na relação lógica entre pergunta e resposta (Sánchez Gamboa, 2013, p. 44).

Entre as vertentes epistemológicas, existem quatro paradigmas que são mais conhecidos, sendo que a última não deveria estar aqui, por razões que contradizem a própria existência desta abordagem, mas está presente apenas para fins didáticos: a abordagem empírico-analítica, a fenomenológica-hermenêutica, a crítico-dialética, e por fim, a pósestruturalista $^{2}$. Por limitações de espaço neste trabalho, o que é mais relevante compreendermos neste momento é a concepção de paradigma. Entre várias opções desse conceito, Romano (1998, p. 67) pode elucidá-lo, demonstrando o poder que cada um desses paradigmas pode apresentar:

\footnotetext{
${ }^{2}$ Para mais informações sobre as abordagens citadas, cf.: LÖWY, Michael. Ideologia e Ciências Sociais, $15^{\mathrm{a}}$ ed. São Paulo: Cortez, 1996. 112 p.; SOKOLOWSKI, Robert. Introdução à fenomenologia. Tradução: Alfredo de Oliveira Moraes. São Paulo: Loyola, 2004. 347 p.; GRONDIN, Jean. Introdução à hermenêutica filosófica. São Leopoldo: Editora da Unisinos, 1999. 335 p. (Focus); PETERS, Michael. Pós-estruturalismo e a filosofia da diferença: uma introdução. Tradução de Tomaz Tadeu da Silva. Belo Horizonte: Autêntica, 2000. p. 96 (Coleção Estudos Culturais; v. 6).
} 
"Paradigma" surge no campo da língua antiga que se liga a deiknumi, cujo sentido é "mostrar", "demonstrar", "indicar". Quando acrescentado da partícula "para", significa "mostrar, fornecer um modelo" [...]. A raiz deik-, por sua vez, refere-se ao ato de "mostrar mediante a palavra", mostrar "o que deve ser", donde a consequência da união com dike a lei, a regra [...].

Se não entrarmos em contato com a literatura de epistemologia, nossa visão conceitual de episteme pode se confundir com o paradigma do positivismo, pois a ciência pode ser equivocadamente conceituada simplesmente como o oposto ao senso comum e constituída de verdades que se comprovavam, mediante experiências empíricas, como podemos observar na designação sobre o paradigma do positivismo:

Os positivistas exigiam que cada conceito presente em uma teoria tivesse como referência algo observável. [...] A aceitação de uma lei ou teoria seria decidida exclusivamente pela observação ou experimento. [...] A verificabilidade seria, portanto, o critério de significação de um enunciado: para todo enunciado com sentido deveria ser possível decidir se ele é falso ou verdadeiro (ALVESMAZZOTTI; GEWANDSZNAJDER, 2001, p. 12).

Outro equívoco que se pode evidenciar, caso não tenhamos clareza sobre a amplitude de paradigmas existentes e suas contribuições para a ciência, pode se manifestar na falsa visão em relação à unicidade de valor de determinados paradigmas que adotamos ao longo de nossa trajetória profissional, considerando, por exemplo, apenas o positivismo ou a fenomenologia como paradigmas válidos ou ainda, apreciando-os como "melhores" que os outros. A dimensão da amplitude da utilização dos outros paradigmas pode ser afetada, podendo não ter a consciência de que a produção de valores de conhecimento não é neutra, pois ela atravessa o campo do poder e dos interesses (CORTELLA, 2001, p. 48).

Também é importante ressaltar que o equívoco anterior pode gerar outro erro: a "ingenuidade científica", que pode ignorar a presença do poder político, revestido em problemas éticos, como Granger (1994, p. 21) aponta:

Os problemas éticos, levantados hoje em dia pelo desenvolvimento das aplicações da ciência só podem ser, em última instância, resolvidos por uma autorregulação consentida pelos próprios cientistas, que, porém, não poderia consistir em proibir a pesquisa de certos saberes, e sim em constatar exatamente sua extensão e suas consequências e, eventualmente, em decidir pausas provisórias, "moratórias" e para reflexão. O papel do poder político, então, não seria mais do que o de consultar sobre esses pontos o conjunto do corpo social, de tirar daí as consequências jurídicas e de controlar sem dúvida autoritariamente, se preciso, as aplicações desses saberes.

O aprisionamento de conceitos de valores científicos pode ocorrer nas análises de produção científica e intervenção profissional; contudo, para nos libertarmos dessa visão 
limitada, é válido estarmos cientes de que existe o pluralismo teórico, assim como também há interesses difusos e disputa por poder.

Diante desse contexto de tensão, conforme pensa Cortella (2001, p. 46), criamos valores que estruturam nossa visão de mundo, de realidade, chegando aos nossos entendimentos, o que caracterizarão os conceitos, que por sua vez, vão à frente de nossas ações, gerando muitas vezes nossos preconceitos. Porém, ao estarmos cientes da contextualização que existe por detrás do conhecimento científico, é possível compreender que: “[...] valores, conhecimentos e preconceitos mudam porque humanos devem mudar; como a vida é processo e processo é mudança, ser humano é ser capaz de ser diferente" (CORTELLA, 2001, p.46.).

Com fins de colocarmos em prática a leitura epistemológica, recomendável na qualificação da produção de conhecimento, seguem na próxima seção deste artigo, alguns apontamentos oriundos dessa leitura, com base teórica em Sánchez Gamboa (2012, 2013), pontuados na dissertação de mestrado de Campos (2008), intitulada: "A adolescência inventada e os sujeitos que se inventam na participação social: capturas e rupturas".

\section{A CONSTRUÇÃo dA PERGUNTA}

O título e o resumo da dissertação de Campos (2008) já determinam algumas pistas para apreendermos qual é a abordagem paradigmática do conhecimento científico que aqui foi empregada. Os termos: captura, ruptura, dispositivo, saber-poder, produção de verdades, cuidado de si, fazer da vida uma obra de arte, o dito e o não dito e resistência denunciam uma inclinação para a teoria foucaultiana, considerando-se assim, a escolha do "paradigma" pósestruturalista. Ressalta-se que Campos (2008) traz também uma abordagem dialética, ao percebermos a presença das contextualizações, das contradições e da dimensão histórica da situação-problema, demonstradas posteriormente.

A importância de ter uma pergunta definida, "plausível de ser formulada quando as condições para a sua resposta estão dadas" (SÁNCHEZ GAMBOA, 2013, p. 44), é condição essencial para fazer ciência. Ao lermos o resumo da dissertação supracitada, pressupõe-se que a pergunta seja: "como os adolescentes encontram novas formas de se relacionar por meio de ações organizadas em suas comunidades?"; a resposta vem em seguida: "a partir de seus fazeres, elaboram saberes que provocam o cuidado de si e do outro, de forma ética" (CAMPOS, 2008, p. 7). 
Uma pista para definirmos o problema da pesquisa é avaliar o risco de termos uma visão superficial da realidade, bem como associarmos questões que já foram resolvidas como se fosse o problema da pesquisa. É mister termos a consciência se existe um problema real ou se este é um pseudo-problema, conforme bem sugere Sánchez Gamboa (2013, p. 103). A situação-problema da pesquisa de Campos (2008.) está clara, descrita no resumo, como uma emergência de se discutir a "adolescência e a possibilidade de ela ser entendida enquanto dispositivo", apresentando "questões que envolvem as relações de saber-poder na produção de verdades e o racismo de estado com relação à adolescência".

No primeiro capítulo, a autora detalha o contexto da pesquisa, enfatizando assim a necessidade concreta da origem do problema, apresentando dados da situação-problema. Explicita com dados estatísticos, quais são os indicadores que justificam a necessidade da pesquisa com adolescentes, por meio da exposição de percentuais quantitativos de estimativa de adolescentes que vivem no mundo, bem como dados que ressaltam a situação de exclusão social desses meninos e meninas, no Brasil e no mundo, levantando informações de taxas de desemprego, e de não acesso à educação (alfabetização), evasão escolar, gravidez na adolescência, criminalidade, entre outros. Ao trazer esses dados quantitativos e qualitativos, provavelmente a autora teve a intenção de justificar o seu problema (CAMPOS, 2008, p. 31$34)$.

Campos (2008) também possui um cuidado em conceituar a adolescência, argumentando os diferentes pontos de vista acerca da faixa etária, desenvolvimento psicossocial, entre outros fatores como o cultural, o social e o político, que interferem e acabam integrando diversas formulações conceituais do que vem a ser o adolescente. Dessa forma, localiza o sujeito e problematiza a necessidade de se trabalhar com adolescência.

\section{A CONSTRUÇÃO DA RESPOSTA}

O recurso metodológico utilizado neste trabalho foi a análise de três textos escritos por adolescentes que participaram de grupos filiados ao Movimento de Adolescentes do Brasil (MAB), como técnicas de coleta na pesquisa, a partir da teoria de Foucault (1971), sobre a escrita de si e o cuidado de si. Essas escritas foram realizadas em três momentos diferentes: segundo a autora (CAMPOS, 2008, p. 23), a primeira escrita foi realizada por solicitação de um jornal da cidade de Rio Claro, a segunda foi fruto de uma oficina realizada nesse mesmo município, com a temática sobre quais foram os diferentes comentários que

\begin{tabular}{|l|l|l|l|l|l|l} 
(C) ETD -Educ. temat. digit. & Campinas, SP & v.16 & n.1 & p.36-47 & jan./abr.2014 & ISSN 1676-2592 \\
\hline
\end{tabular}


ouviam sobre a "adolescência" quando ainda eram crianças, e a terceira foi enviada por email para a pesquisadora, por meio do MAB.

A autora sistematizou os dados coletados a partir de argumentações com as bases teóricas que interligavam-se entre si (CAMPOS, 2008), bem como reflexões sobre músicas, poesias e poemas acerca do tema tratado, combinando com a análise da construção do discurso, presente nas três escritas dos adolescentes. O motivo de Campos (2008, p. 24) ter escolhido essa técnica de coleta de dados está na curiosidade de descobrir como os adolescentes "se pensam" como pessoas, e qual o olhar que eles tinham sobre suas experiências.

No nível teórico, a autora (CAMPOS, 2008, p. 34-36) faz uma análise crítica dos efeitos do poder, exemplificando a mídia como um dos vetores que institui uma imagem cristalizada e estigmatizada, ao afirmar que "adolescente é tudo igual, que é uma massa homogênea, incolor". Esclarece ainda que, pela pesquisa é possível distorcer o real e desprezar as singularidades e subjetividades, para pressupor que há possibilidades de dominação sobre o que é igual. A autora ressalta que é difícil dominar o anônimo, o que contraria os iguais. Outra crítica amplamente discutida nesse trabalho diz respeito ao racismo de Estado em relação à adolescência, disponibilizada no capítulo dois:

Por racismo de Estado, Foucault (1999) entendeu "um racismo que uma sociedade vai exercer sobre ela mesma, sobre os seus próprios elementos, sobre os seus próprios produtos; um racismo interno, o da purificação permanente, que será uma das dimensões fundamentais da normalização social" (CAMPOS, 2008, p. 73).

Nessa dissertação, vemos a interpretação dos resultados dos dados coletados a partir das teorias utilizadas por Foucault (1971), especialmente, em relação à escrita de si, pois é justamente na análise da escrita que Campos (2008, p. 45) privilegia a oportunidade de "poder olhar para si, para a vida e para o mundo"; a experiência de "registrar-se", "irá favorecer a experiência do cuidado de si, do exercício desse cuidado e da descoberta do outro".

A autora organiza e apresenta seus resultados inicialmente mostrando cada escrita dos adolescentes na íntegra, e em seguida, por fragmentos dessas escritas, realiza suas argumentações, dedicando-se a essa prática do primeiro ao terceiro capítulo. Um exemplo dessa forma de analisar a escrita em seus fragmentos está na discussão da maneira de como ser adolescente. Campos (2008, p. 45) apresenta a primeira escrita de uma das adolescentes e a interpreta, argumentando criticamente contra outros teóricos, citando como exemplos Tiba

\begin{tabular}{l|l|l|l|l|l|l} 
(C) ETD - Educ. temat. digit. & Campinas, SP & v.16 & n.1 & p.36-47 & jan./abr.2014 & ISSN 1676-2592
\end{tabular}


(1986) e Margaret Mead (1971), que ao utilizarem conceitos "classificatórios", "universalizantes" e "normalizadores" cristalizam o que é viver a adolescência. A autora ainda argumenta que são produzidos discursos que obedecem a determinadas ordens, em torno do tema da adolescência: “[...] pode-se constatar que a nossa cultura concebe a "adolescência" como um problema, uma soma de situações embaraçosas que precisam ser vigiadas e controladas" (CAMPOS, 2008, p. 51).

Tendo em vista que temos elementos suficientes para identificar a pergunta e a resposta na dissertação de Campos (2008), podemos aprofundar nossa leitura nos aspectos epistemológicos, gnosiológicos e ontológicos na elaboração da resposta.

\section{PRESSUPOSTOS EPISTEMOLÓGICOS, gNOSIOLÓgICOS E ONTOLÓGICOS}

Ao designar o objeto e o sujeito e relacioná-los ao processo de produção de conhecimento, temos os pressupostos gnosiológicos, que podem variar de acordo com a abordagem paradigmática escolhida pelo pesquisador). Os pressupostos ontológicos constituem a concepção de homem, de história e realidade. (SÁNCHEZ GAMBOA, 2012, p. 98-99).

Em relação à visão de homem, Campos (2008, p. 26) considera a cultura e a história com primazia, como observamos a seguir:

[...] viver em uma dada sociedade, ter uma determinada idade, pertencer a uma classe social, ser homem, mulher, são fatores que interferem na realidade, na forma como cada pessoa vive sua história e suas relações com a natureza, com a cultura e com outros seres humanos.

Os sujeitos de sua pesquisa - os adolescentes - estão inseridos no contexto da sociedade no presente conjuntural e a autora deixa claro que conviver em sociedade sujeita os indivíduos às normas pré-estabelecidas e que o discurso também deve ser considerado como peça relevante para compreensão dos rumos do jogo dos efeitos do poder, em especial, o que opera no meio midiático (CAMPOS, 2008, p. 34).

Como já explicitado anteriormente, Campos optou por dimensionar o tempo e o espaço historicamente, designando o aspecto diacrônico em sua pesquisa ao privilegiar a realidade dinâmica, apontando, por exemplo, um resgate histórico sobre o surgimento do conceito de adolescência (CAMPOS, 2008, p. 27). Dessa forma, os fenômenos são situados dentro do processo histórico, em movimento e em conflito de contrários, conforme conceitua Sánchez Gamboa (2012, p. 100).

\begin{tabular}{l|l|l|l|l|l|l}
\hline (C) ETD - Educ. temat. digit. & Campinas, SP & v.16 & n.1 & p.36-47 & jan./abr.2014 & ISSN 1676-2592 \\
\hline
\end{tabular}


A autora não expõe argumentos referentes à conceituação sobre ciência, mas se pensarmos na sua definição, considerando a abordagem paradigmática pós-estruturalista abordada pela autora em seu referencial teórico central, nos depararemos com a oposição da definição de ciência, ao utilizar Foucault (1971) citado por Campos (2008, p. 51):

[...] no caso em que se pudesse descrever, entre um certo número de enunciados, semelhante sistema de dispersão, no caso em que entre os objetos, os tipos de enunciação, os conceitos, as escolhas temáticas, se poderia definir uma regularidade (uma ordem, correlações, posições e funcionamentos, transformações), dir-se-á, por convenção, que se trata de uma formação discursiva - evitando, assim, palavras demasiado carregadas de condições e consequências, inadequadas, aliás, para designar semelhante dispersão, como "ciência", ou "ideologia", ou "teoria", ou "domínio de objetividade".

Em relação à cosmovisão, compreende-se como “[...] uma percepção organizada da realidade que orienta a produção de investigação e organiza os diversos elementos implícitos que constroem a prática cotidiana do pesquisador" (SÁNCHEZ GAMBOA, 2013, p. 100). Nesse sentido, a autora refere-se a duas linhas de pensamento, dentro de sua cosmovisão: transformação social e ruptura. A primeira, de forma dialética, na citação a seguir: "tenho visto adolescentes que conseguem agir de forma a transformar o mal-estar vivido criando alternativas e superando os obstáculos" (CAMPOS, 2008, p. 90). Na segunda maneira, Campos (2008, p. 149) menciona a transformação social como ruptura e, ainda, como linhas de fuga,

[...] com sua disposição em entender o poder e a resistência como forças que movem, que provocam as mudanças e tornam possíveis as rupturas e as invenções de novas formas de vida.[...] Fugir, é poder, a partir do que se tem, criar novas rotas, novas formas de fazer, de propor e de mudar (DELEUZE; PARNET, 1998 citado por CAMPOS, 2008, p. 93).

A respeito do conceito de educação, Campos situa em seu trabalho a educação não formal, por sua pesquisa tratar de adolescentes vinculados à instituição chamada MAB. $\mathrm{O}$ conceito empregado é o de "educação menor", cunhado por Gallo (1976) e citado por CAMPOS (2008, p. 43), com inspiração em Deleuze. A autora justifica que esse conceito de educação menor é apresentado em função da inclusão da arte nas periferias, como modo de apreciá-la ou vivenciá-la, também caracterizada por arte menor:

Para aquém e para além de uma educação maior, aquela das políticas dos ministérios e secretarias, dos gabinetes, há também uma educação menor, que nos permite sermos revolucionários, na medida em que alguma revolução ainda faz sentido na educação em nossos dias. A educação menor constitui-se, assim, num empreendimento de militância (CAMPOS, 2008, , p.169). 
No memorial da autora, percebemos o contato com a educação e o educar ainda na infância, perpassando sua trajetória profissional na educação especial, arte-educação, educação não formal, educação privada, entre outros. Quando pedagoga, como formação inicial, Campos (2008, p. 135) cita sua experiência quanto as leituras de Paulo Freire desde os 11 anos de idade, quando recebeu a missão dada por seu pai para alfabetizar uma família de um preso que havia cometido homicídio. As raízes da vertente paradigmática crítico-dialética podem ainda prevalecer ao longo de boa parte da argumentação da autora em sua dissertação, talvez pelo fato de a autora ter imergido desde muito cedo nas leituras freirianas.

\section{CONCLUSÃO}

Este artigo teve a pretensão de suscitar a curiosidade sobre os motivos pelos quais é importante compreender a epistemologia, mesmo que seja para pensar com ou contra ela, ou a partir dela. Espera-se que após feita uma leitura epistemológica de uma pesquisa concluída na área da educação, tenha despertado o pensar sobre nossos próprios limites, erros, acertos, escolhas, valores e anseios ao trabalharmos com o conhecimento científico.

Lembrando que, para fazer ciência, o mínimo que se espera do pesquisador, cientista ou outro profissional que esteja envolvido nesse processo seja a curiosidade. Ter perguntas e procurar as respostas é produzir conhecimento científico. O exercício de fazer a leitura epistemológica, seja para buscarmos o conhecimento, seja para produzi-lo, se faz pertinente para qualificar a pesquisa científica e evitar equívocos, como lacunas ou excesso de informações que se transformam nas "pérolas da redação científica", como alerta Volpato (2010). Um dos trunfos para evitar que sejamos vítimas dessas "pérolas" é fazer o exercício de ir e voltar nas perguntas e respostas, ou seja, "explicar (do todo para as partes) e compreender (das partes para o todo)", a partir do método geométrico (SÁNCHEZ GAMBOA, 2013 p. 64).

Se houver a percepção de que as hipóteses de uma pesquisa não são compatíveis com os resultados obtidos, não é transgressão alguma alterá-las. Para Alves-Mazzoti e Gewandsznajder (2001, p. 63), ser crítico é admitir a possibilidade de erro. Assumi-lo é um avanço para a ciência.

Aos termos clareza e consciência do que são os paradigmas, notamos a importância de sua superação, ao entender que os paradigmas podem nos mostrar como o mundo se 
transforma. Compreendemos assim, porque os paradigmas são criados e porque são superados.

Um dos desafios na Universidade é aceitar a pluralidade dos paradigmas. Infelizmente, em muitos grupos de pesquisa, o efeito de disputa entre as abordagens paradigmáticas surte como guerra de todos contra todos, como se tais abordagens fossem dogmas ou até mesmo, correntes religiosas. Em vez de disputa, poderia surgir um debate saudável com respeito e a consciência de que, não é por causa de um paradigma ter sido superado que este deve ser descartado. Pelo contrário, existe sua valia, que historicamente foi aceita no meio acadêmico. De qualquer forma, quando isso ocorre, invariavelmente estamos fazendo uma leitura do método dialético, pois se há superação de um paradigma em detrimento de outro, isso é dialética!

Ter consciência do que é fazer ciência norteia trabalhos qualificados para o contexto da educação brasileira, pois em relação à clareza e consciência dos paradigmas, quando somos confrontados com pensamentos distintos (tese) de nosso pensamento "velho" (antítese), este processo implica em contradições e dicotomias, e podemos assim construir um novo pensamento (síntese), nos tornando pesquisadores mais flexíveis, tolerantes e com abertura para o novo.

Nesse sentido, é oportuno o pensamento de Cortella (2001, p. 50), quando enfatiza que os educadores e as educadoras deveriam priorizar a compreensão da gênese e seus desdobramentos em relação aos valores e conhecimentos, dados pelas determinações da natureza humana em movimento de superação e não estáticos e imóveis.

Hoje são validados o positivismo, o marxismo, a hermenêutica, o pós-estruturalismo, entre outras abordagens, e todos esses paradigmas são capazes de promover perguntas e problematizar, ou seja, todos nós somos capazes de produzir conhecimento, basta fazermos bom uso das ferramentas que teremos em mãos a partir do significado, das contribuições e do contexto que permeia a epistemologia, rompendo com visões cristalizadas.

\section{REFERÊNCIAS}

ALVES-MAZZOTTI; Alda Judith; GEWANDSZNAJDER, Fernando. O método nas ciências naturais e sociais. São Paulo, SP: Pioneira, 1998. 203 p.

CAMPOS, Maria Teresa de Arruda. A adolescência inventada e os sujeitos que se inventam na participação social: capturas e rupturas. 2008. 187 f. Dissertação (Mestrado em Educação) - Faculdade de Educação, Universidade Estadual de Campinas, Campinas SP, 2008.

\begin{tabular}{l|l|l|l|l|l|l} 
(C) ETD - Educ. temat. digit. & Campinas, SP & v.16 & n.1 & p.36-47 & jan./abr.2014 & ISSN 1676-2592
\end{tabular}


CORTELLA, Mario Sergio. A escola e o conhecimento: fundamentos epistemológicos e políticos. 4. ed. 2001; São Paulo, SP: Cortez; Instituto Paulo Freire, 166 p. (Coleção Prospectiva, $5)$;

DELEUZE, Gilles; PARNET; Claire. Diálogos. Tradução Eloisa A. Ribeiro. São Paulo, SP: Editora Escuta, 1998. 184 p.

FOUCAULT, Michel. A Arqueologia do Saber. Petrópolis, RJ: Vozes, 1971. 256 p.

GALLO, Silvio. Em torno de uma educação menor. Educação \& Realidade, Porto Alegre, , v.1, n.1, p. 169-178, fev.1976.

GRANGER, Gilles-Gaston. A ciência e as ciências. Tradução Roberto Leal Ferreira. São Paulo (SP): Editora da Universidade Estadual Paulista, 1994. 122 p.

MEAD, Margaret. Adolescencia y cultura en Samoa. Barcelona: Paidós, 1971. Apud CAMPOS, Maria Teresa de Arruda. A adolescência inventada e os sujeitos que se inventam na participação social: capturas e rupturas. 2008. 187 f. Dissertação (Mestrado em Educação) - Faculdade de Educação, Universidade Estadual de Campinas, Campinas, SP, 2008.

ROMANO, Roberto. A crise dos paradigmas e a emergência de reflexão ética, hoje. In:

Educação \& Sociedade, Campinas, SP, v. 19, n. 65, p. 65-100, dez.1998. Disponível em: $<$ http://www.scielo.br/scielo.php?script=sci_arttext\&pid=S0101$73301998000400003 \& \operatorname{lng}=$ en\&nrm=iso $>$. ISSN 0101-7330. http://dx.doi.org/10.1590/S0101-73301998000400003.> Acesso em 22 de jan. 2014.

SÁNCHEZ GAMBOA, Silvio . Pesquisa em educação: métodos e epistemologias. 2. ed. Chapecó: Argos, 2012. 212 p.

SÁNCHEZ GAMBOA, Silvio. Projetos de pesquisa, fundamentos lógicos: a dialética entre perguntas e respostas. Chapecó: Argos, 2013.159 p.

VOLPATO, Gilson. Pérolas da redação científica. São Paulo, SP: Cultura Acadêmica Editora. 2010. 188 p.

TIBA, Içami. Puberdade e "adolescência": desenvolvimento biopsicossocial. São Paulo, SP: Agora, 1986. $231 \mathrm{p}$. 


\section{Agradecimentos}

Agradeço a CAPES pelo financiamento deste trabalho.

\section{Como citar este documento:}

RODRIGUES, Susy Cristina. Valorizando a leitura epistemológica na pesquisa em educação. ETD Educ. temát. digit., Campinas, SP, v. 16, n. 1, p. 36-47, jan./abr. 2014. ISSN 1676-2592. Disponível em: <http://www.fae.unicamp.br/revista/index.php/etd/article/view/5728>. Acesso em: 30 Abr. 2014. 